\title{
Enterprise Architecture Oriented Requirements Engineering for the Design of a School Friendly Open Data Web Interface
}

\author{
Mubashrah Saddiqa $^{1 \star}$, Marite Kirikova $^{2}$, Rikke Magnussen $^{3}$, Birger Larsen $^{3}$, \\ and Jens Myrup Pedersen ${ }^{1}$ \\ ${ }^{1}$ Department of Electronic Systems, Aalborg University, Aalborg, Denmark \\ ${ }^{2}$ Institute of Applied Computer Systems, Riga Technical University, Riga, Latvia \\ ${ }^{3}$ Department of Communication and Psychology, Aalborg University, Aalborg, Denmark \\ mus@es.aau.dk, marite.kirikova@rtu.lv, rikkem@hum.aau.dk, birger@hum.aau.dk, jens@es.aau.dk
}

\begin{abstract}
Open Data is considered a key to scientific innovations. These freely available datasets can also be used as a foundation to enhance the digital and data literacies among the younger generation of school pupils. This article presents the design and prototype of an Open Data web interface based on the Enterprise Architecture Oriented Requirements Engineering (EAORE) approach for Open Data usage as an educational resource in Danish public schools. We first systematically review the literature on Open Data use in educational fields and selected 14 research articles with a particular focus on the use of Open Data in the educational domain after prescribing an inclusion/exclusion criteria on 101 research articles identified initially. The review indicates that there is a gap between Open Data opportunities within the educational domain and in exploring the use of Open Data as a source to develop twenty-first-century skills, specifically digital and data literacies among younger school pupils. To fill this gap, we propose an EAORE approach that represents how Enterprise Architecture (EA) models can guide the overall Requirements Engineering (RE) process for the use of Open Data in Danish public schools. Based on these EA models, we designed the prototype of an Open Data web interface for schools.
\end{abstract}

Keywords: Enterprise Architecture, Requirements Engineering, Open Data, Open Data Web Interface, Educational Resource, Digital Literacy, Data Literacy.

\section{Introduction}

The work in this article is an extension of our initial study reported in [1]. As novel contributions, we present (1) a systematic literature review on the use of Open Data in different educational sectors, (2) a research gap identified in exploring the educational opportunities offered by Open Data, and

\footnotetext{
^ Corresponding author

(c) 2019 Mubashrah Saddiqa et al. This is an open access article licensed under the Creative Commons Attribution License (http://creativecommons.org/licenses/by/4.0).

Reference: M. Saddiqa, M. Kirikova, R. Magnussen, B. Larsen, and J. M. Pedersen, "Enterprise Architecture Oriented Requirements Engineering for the Design of a School Friendly Open Data Web Interface," Complex Systems Informatics and Modeling Quarterly, CSIMQ, no. 21, pp. 1-20, 2019. Available: https://doi.org/10.7250/csimq.2019-21.01

Additional information. Author ORCID iD: M. Saddiqa - https://orcid.org/0000-0002-4816-2426, M. Kirikova - https://orcid.org/0000-0002-1678-9523, R. Magnussen - https://orcid.org/0000-0001-8058-9027, B. Larsen https://orcid.org/0000-0002-3622-2698, J. M. Pedersen - https://orcid.org/0000-0002-1903-2921. PII S225599221900121X. Article received: 2 November 2019. Accepted: 5 December 2019. Available online: 31 December 2019.
} 
(3) the design and prototype of an Open Data web interface proposed as the result of an Enterprise Architecture Oriented Requirements Engineering (EAORE) process.

Open Data is openly available datasets permitting citizens to freely use, modify, and share them for any purpose [2]. Open Data is open to everyone, i.e. citizens, businesses, non-profits, public administrations, and technologists. It is a resource that can potentially promote democracy, transparency, civic engagement, efficient public services, and economic growth. Open Data opportunities and benefits could significantly increase if citizens were able to use that data effectively and efficiently [3], [4]. Hence, citizens' active engagement is vital to harness the power of Open Data. However, Open Data discussions and research typically focus more on the technical side, e.g. collection, storage, availability, and licensing, and have largely neglected issues related to the public and its consequent use by citizens [5], [6]. These issues include such questions as which datasets the public needs, how Open Data can be used as an educational resource, and how citizens can be engaged in exploiting available Open Data. We believe that it is important to engage younger school pupils with Open Data to equip future generations with essential learning skills. Open Data can act as a key to develop twenty-first-century skills such as enhancing critical thinking, digital and data literacy skills and civic awareness among pupils [7]. Hence, Open Data is not only a potential resource of opportunities for the public (e.g. to improve public services, to bring greater transparency, etc.); it could also act as twenty-first-century raw material to develop digital and data skills among public school pupils, as well as a source to inform them about their communities. However, the educational use of these openly available datasets is so far very limited - particularly in schools to facilitate teaching activities using Open Data as part of different subjects.

Many open datasets that could be used as part of teaching materials are available on various countries' Open Data portals. Public schools could experiment with these openly available datasets to grow public engagement and to develop digital and data skills, as well as to foster civic awareness among younger pupils. For instance, as part of a chemistry class, pollution levels, noise levels, and water quality datasets can provide up-to-date knowledge about local areas. Pupils can further discuss why the levels are high or low, and how they could work to improve the situation [8]. Open datasets can be used as educational resources to support teaching of a wide variety of subjects and to permit pupils to work with the actual datasets to develop new learning skills. Hence, several countries have started taking initiatives and launching different projects to introduce the possible opportunities of Open Data [9] to the younger generation of pupils. The work reported in this article is part of the Copenhagen Community Drive project [10] that particularly focuses on the city's many types of data and how to put them into use, primarily in an educational context. The project focuses on how and to what extent existing Open Data can facilitate the educational process in Danish public schools, and how we can integrate Open Data and associated technologies in schools in a way that benefits pupils' digital and learning skills.

To facilitate educational activities using different forms of data Alper et al. [11] recommends that appropriate datasets should be visualized in simple graphs, e.g. bar, pie, or line graphs. The availability of interesting datasets through Open Data could allow both, teachers and pupils to develop data literacy skills. However, even such relatively simple use of data requires considerable effort by teachers, and they may need data analytic skills, e.g. to fragment the bigger datasets into smaller datasets and make visualizations. We propose to develop an Open Data web interface that can facilitate public schools to stimulate the Open Data usage in elementary schools by allowing teachers and pupils to relate their subjects to the actual information of their local areas and compare the data with that of other communities in the form of simple visualizations. However, for the development of such an interface, it is essential to identify the requirements of teachers and pupils. To the best of our knowledge, there exist no guidelines for the requirements engineering process for usage of Open Data in schools as an educational resource. This article makes a step towards defining best practices for such situations using principles of Requirements Engineering (RE) within an Enterprise Architecture (EA) framework. We start from the following research question: 
"How can enterprise architecture guide the requirements engineering process to establish needs and requirements of teachers and pupils in relation to stimulating the use of Open Data as an educational resource in Danish public schools?" We believe that the obtained results are sufficiently general and might be interesting for other researchers working in the domain of Open Data applications. We use EA models to help elicit requirements for the development of the Open Data web interface for schools using EAORE approach. The interface could enable teachers to relate their subjects to actual Open Data, e.g. pollution level, noise level, or traffic congestion near the schools. In this work, RE and EA have been integrated to investigate the problem, specify solutions, and validate the solutions for the development of an Open Data web interface that allows teachers to use Open Data as an educational resource at public schools.

The structure of the article is as follows: In Section 2, we present a systematic literature review on the use of Open Data in the educational domain. In Section 3, we discuss the research methods and related work regarding requirements identification. In Section 4, we outline our proposal for an Enterprise Architecture Oriented Requirements Engineering (EAORE) approach in the context of Open Data usage in schools along with the design of the Open Data web interface in Section 5. We provide brief conclusion in Section 6.

\section{Literature Review}

In recent years, Open Data has gained massive attention, and many countries have started publishing data that is open for the public [12]. The use of these real datasets is nonetheless generally limited to government, business, and research institutes. Many researchers have taken initiatives to investigate how these real datasets could be used in domains other than industry and government. Moreover, literature exists within the research community that explores different factors that influence the use of Open Data by citizens [13]. There have been many systematic literature reviews on the technical side of Open Data, and topics include the usage of open government data [14], Open Data initiatives [15], the publishing of Open Data [16], and classification, perspectives, benefits, and barriers of Open Data [17]. However, the possibilities and opportunities for Open Data usage in the domain of education have largely been overlooked. Among few researches within this domain, Atenas et al. [7] discussed the use of Open Data as educational resources in higher education. The authors used case studies to explore the utilization of Open Data as a form of educational resource with higher education students. They discussed different ways that Open Data could help to develop transversal skills among students.

In this article we claim that these real datasets can also facilitate educational activities of younger school-children specifically, pupils from fifth grade and onwards (mostly pupils start working with different forms of data from grade fifth and above). As a research contribution, we present a systematic review of the educational use of Open Data in education.

\subsection{Review Methods}

A systematic mapping review method [18], [19] was applied to map and classify the research literature to identify any gaps for the research community (see Figure 1). The design of the literature review consists of a careful collection of research articles, an analysis of these articles, and a systematic mapping of the findings. The review considers only research papers about Open Data usage in teaching, learning, and developing skills among younger pupils. The literature is discussed in four broad categories: (1) the motivation for using Open Data as an educational resource, (2) the use of Open Data in higher education, (3) the use of Open Data in elementary education, and (4) the use of Open Data in developing educational tools to assist different teaching activities. The objective of the review is to present a comprehensive overview of relevant academic literature on these four categories and to identify gaps for future research. For this we identify different forms of the use of Open Data in educational settings, including the development of tools and technologies based on Open Data in the educational domain. 


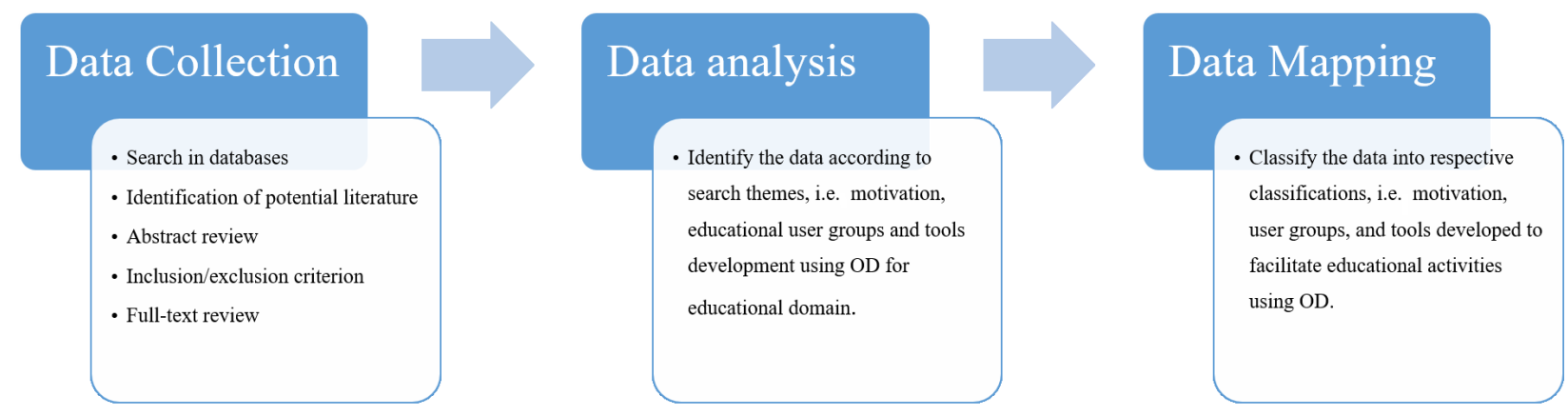

Figure 1. Overview of systematic mapping review method inspired by [19]; OD - Open Data

\subsubsection{Collection of Research Articles}

We utilized the following search engines for data collection:

- Scopus

- ACM Digital Library

- Web of Science

- Google Scholar.

The phrases "open data as an educational resource", "open data in schools", "using open data in teaching", "open data and education", "open data usage in schools", and "educational use of open data" were used to search the various databases in the title, abstract, and keywords of the articles.

\subsubsection{Selection}

To reduce the risk of bias, we implemented clear inclusion and exclusion criteria:

- Only peer-reviewed research articles in English were included.

- Only Open Data studies were included in which the focus was on the educational domain.

- We only considered studies that focused on one or more of the following dimensions: motivation for using Open Data as an educational resource, the use of Open Data in the educational domain, and the development of tools based on Open Data for educational use.

Table 1 represents the overall number of initially identified studies. To avoid duplication, we chose the articles retrieved from the first database (the ACM Digital Library) and then only considered new papers from the rest of the databases. 101 research articles were initially retrieved using the search phrases mentioned above. After the screening of titles, keywords and excluding the articles that were not peer-reviewed, 45 articles were selected for the screening of abstracts. After careful screening of abstracts, fourteen research articles were selected for data analysis that fulfilled the inclusion and exclusion criteria mentioned above.

Table 1. Initial search results for data collection

\begin{tabular}{|l|l|l|l|}
\hline Search Engines & Initial Search Results & Abstract Screening & Selected Studies \\
\hline Scopus & 39 & 15 & 3 \\
ACM & 46 & 21 & 7 \\
Web of Science & 6 & 4 & 2 \\
Google Scholar & 10 & 5 & 2 \\
\hline Total & $\mathbf{1 0 1}$ & $\mathbf{4 5}$ & $\mathbf{1 4}$ \\
\hline
\end{tabular}

To classify the research articles into different categories for analysis, we followed an approach for thematic analysis discussed in [19]. The thematic categories were specified by identifying and mapping the reviewed articles for Open Data usage within the educational domain. 


\subsection{Review Findings}

Table 2 shows an overview of the papers included in the review and classified into the four categories discussed above.

Table 2. Outline of reviewed articles and identified categories

\begin{tabular}{|l|c|l|}
\hline \multicolumn{1}{|c|}{ Categories } & First Author and Reference & No. of Articles \\
\hline Motivation & Atenas [20], Tim [21], Manca [22] & 3 \\
\hline Open Data usage in higher education & $\begin{array}{c}\text { Renuka [23], Shamash [24], Love [25] } \\
\text { Tim [26], Perez-del-Hoyo [27], Anslow [28] }\end{array}$ & 6 \\
\hline Open Data usage in elementary schools & Annika [29], Saddiqa [8], Saddiqa [30] & 3 \\
\hline Open Data tools for educational use & Dunwell [31], Marie Friberger [32] & 2 \\
\hline
\end{tabular}

\subsubsection{Motivation for Using Open Data}

Open Data has many aspects that could benefit the educational domain, for instance, the internal element, the scientific side, and its power to bring transparency and accountability. In connection with the educational use, the inner and scientific aspects act as elements for the motivation of Open Data usage in education [7]. For instance, the subjective element allows pupils to learn and solve problems and to understand their real world. With the scientific element of Open Data, pupils and teachers could re-use this data to develop knowledge in other educational fields. However, the limited research to date on Open Data usage in teaching suggests a lack of awareness among educators. There is little research on why or how Open Data should be employed in teaching practices.

[20] explores the fundamental ways to support educators in empowering pupils with essential twenty-first-century skills. The study investigated how the use of Open Data can be a key to the development of transversal skills, including digital and data literacy. [21] investigated the value and challenges of using Open Data in education through the vision of early adopters of Open Data. The author presents a qualitative descriptive design to understand the perspective of Open Data usage in teaching through interviews. By working with early adopters, the author identifies that Open Data has potential as authentic and relevant material that expands the possibilities for learning activities. The study further identified that learners and educators lacked data literacy or resources to make full use of Open Data opportunities. Manca et al. [22] discussed another aspect of Open Data when used as an open educational resource. According to this study, Open Data can act as a powerful resource for learners in the context of post-traumatic societies when supported by a critical pedagogy scaffolding.

\subsubsection{Open Data Usage in Higher Education}

The review reveals that most users of Open Data in educational domains were higher education students. The students typically use Open Data in their research projects or assignments to develop digital and data skills. [23] investigates how undergraduate students could benefit from the vast amount of data in different fields. The study aimed to engage the student community with the data to increase their effective domain learning, and make them realize the vast potential that raw data holds for them. The results showed that suggesting and introducing the concepts of research and harnessing the massive amount of Open Data enabled them to produce useful results for society. [24] describes experiences of a case study in how a group of masters degree students learned the value and limits of working with quantitative data. The students picked a dataset and an API of their own choice (Twitter, VPL, Biblioshare, CrossRef, etc.), combined them using Google Refine, and cleaned and manipulated the data for analysis. The case study showed the value of using openly available data in the classroom and how the Open Data ecosystem encouraged the students to share 
their insights and results and gaining a sense of belonging to a community and a sense of pride in doing meaningful work. In [25], the authors describe an assignment investigating the relationship between weather conditions and levels of air pollution. The case study illustrates aspects of finding and accessing Open Data, sections of the extract-transform-load processes of data warehousing, building an analytic cube, and the application of data mining tools. The case study raises several questions about what makes a good assignment for students learning to handle data and about the use of Open Data in students' assignments. A similar study [26] reports results from a case study that explores why and how Open Data can be used as material to produce engaging challenges for students when they are introduced to programming. Through describing the process of creating the assignments, the author suggests that Open Data is robust material for designing learning activities because of its qualities of ease of access and authenticity. [27] discusses the experiences from the University of Alicante. The experiment involved introducing students to a smart consumption of information along with its analysis and interpretation. The study indicated that the opportunity to operate with freely accessible, large geo-referenced databases represents an excellent potential for research and instruction in engineering education. [28] emphasizes the need to increase the data literacy of computer science students. To address the needs of student data science and analytic skills, the authors proposed augmenting existing data science curriculum with 'hackathon-type' events (in which a large number of people meet to engage in collaborative computer science events) that focus on data, also known as 'datathons'. The authors presented the experiences of hosting and running four datathons that involved students and members from the community coming together to solve challenging problems with data from not-for-profit social welfare organizations and public Open Data. The authors suggest that with the increase in data amounts, there will be a need for people to learn and increase their skills with key data science and analytic techniques and tools to make better informed decisions.

\subsubsection{Open Data Usage in Elementary Schools}

Not much literature within the research community exists focusing on the use of Open Data in elementary schools. [29] describes an approach to teaching data skills in schools using real-life, sophisticated urban datasets collected as part of a smart city project. The approach was founded on the premise that young learners have the ability to work with complex datasets if they are supported in the right way, and if the tasks are grounded in a real-life context. Narrative principles were used to frame the task, to assist interpretation, to tell stories from the data, and to structure queries of the datasets. The study participants were twelve pupils aged 9-10 years from a UK primary school. The pupils learned about home energy consumption and the generation of solar energy from home solar photovoltaic (PV) technology, by interpreting existing visualizations of smart meter data and data obtained from an aerial survey. Saddiqa et al. [8] presented survey results of Open Data visualization in Danish public schools. The authors conducted interviews and set up pilot tests to introduce and investigate the scope of Open Data visualizations in elementary schools for fifth grade and above. The results showed that simple Open Data visualizations about the pupils' own municipalities attracted their attention and encouraged discussions and reflections. Teachers were highly positive, but they needed ready-to-use datasets as part of teaching assignments. Also, for young pupils, the concept of Open Data was very abstract. To develop data skills, the authors suggested designing different activities for data collection as part of learning assignments. In another study, Saddiqa et al. [30], identified Open Data domains that could easily facilitate basic school subjects, such as mathematics, science, social science, and geography, and presented example datasets to teachers in interviews and by setting up observations with a group of pupils attempting to make the use of the datasets. The authors highlighted different challenges in using Open Data at the school level. Teachers needed extra time or data analytic skills to use these real datasets in their class environments. In addition, most of the visualization tools were available in English only, which 
was also considered a hurdle for engaging the elementary schools with Open Data, when the pupils are non-native speakers of English.

\subsubsection{Development of Open Data Tools for Educational Use}

In this category, the focus is on research where efforts are made to develop tools and technology based on Open Data specifically for educational use. [31] describes the approach adopted by a serious game supporting the development of healthy lifestyles amongst adolescents using the United States Department of Agricultures Open Data on nutritional information. The game itself places the player as a survivor in a post-apocalyptic scenario, tasked with survival and exploration. The results showed how standard game mechanics can be applied to Open Data to provide useful and engaging educational experiences. The author of [32] contributed in her research to the ever-growing list of things that can be done with games by proposing, discussing, and exemplifying data games. Data games differ from most other types of serious games in as they do not (intentionally) have an agenda; they are tools for the player to use to explore data with as few constraints as possible. Data games complement the Open Data and linked-data movements, as the growing amount of data that is available in this way is a good fit for game-based exploration. The author, as an example, describes Open Data Monopoly. With this type of game, pupils can be provided with a means of visualizing publicly available data about their countries and neighborhoods. As web-based Open Data sources become increasingly accessible and active, translating and re-purposing this data towards an educational goal is a topic of interest [33]. Games can provide a key medium through which this may be achieved, though limited evidence exists with regards to the best techniques, both pedagogical and technological, by which data can be translated into engaging and educational material.

The results of the current review show that the majority of studies of Open Data usage in education have been conducted with a focus on the use of Open Data in higher education. The described categories (motivation, Open Data usage in elementary schools, and Open Data tools for educational use) need to be explored in more depth in future research. With the advancement in digital technologies and access to real datasets on our communities, it becomes crucial to equip our next generation with essential future skills, mainly in digital and data capabilities. For this, teachers and pupils must be aware of and able to use available open resources that allow them to develop these essential skills. Therefore, in future research to fill this gap, our focus will be on the motivational aspect of Open Data usage in education to make educators aware about the educational potentials of Open Data and how Open Data could benefit elementary public school pupils in developing digital and data literacy. There is also a need for developing Open Data tools and technologies that could facilitate teaching activities.

\section{Research Methods and Related Work Regarding Requirements}

The research approach used to design the approach for requirements identification in the context of Open Data usage in schools consisted from the following steps:

1. Analyze open datasets of the target domains.

2. Identify Open Data impact domains that may facilitate teaching.

3. Analyze available data visualization tools.

4. Survey Danish schools to learn teachers and pupils' perspectives on Open Data.

5. Envision a possible solution for Open Data usage in schools.

6. Propose an approach for the identification of requirements for the envisioned solution.

To analyze open datasets of the target domains, we accessed the open datasets through national Open Data portal of Denmark ${ }^{4}$ where cities, organizations, and researchers publish data that may

4 http://www.opendata.dk/ 
be useful for the public. This data source is used to develop different mobile applications and improve public services to bring benefits to the citizens of Denmark. In order to use open datasets as educational resources in Danish public schools, we carefully analyzed open datasets of the city of Copenhagen, the capital of Denmark. Copenhagen has more than 290 open datasets from different sources, accessible from the national Open Data portal of Denmark. These datasets include information of various types, for instance, graphical data, statistical data, and live data; and this data is available in different formats (such as CSV, PDF, JSON, etc.).

We identified four impact domains, or educational domains: environment, demographics, geographical, and statistical data, that have the potential to easily facilitate teaching as a part of primary public school subjects, such as science, social science, geography, and mathematics. Some open source data visualization tools were also analyzed for their possible adoption in visualizing Open Data. We also surveyed ten Danish public schools to understand teacher and student perspectives in Open Data usage. This work is discussed in [8] and [30]. Teachers were very positive about the potential to facilitate teaching with actual data, but they required ready-to-use datasets and visualizations as part of teaching assignments. In addition, it was mentioned that the available open-source tools for visualization were not in Danish, which was also considered a hurdle for the presentation of Open Data at the school level in Denmark. Teachers requested an overview of what datasets were available and pointed to the fact that it required both the time and skills of teachers to present the right information to the pupils. Hence, the development of an Open Data web interface that enables pupils and teachers to select datasets within educational themes and aids in visualizing the data in the form of simple graphs, comparing data between areas, and designing activities to explore more data as part of respective subjects, could address the above described issues. For the development of the Open Data interface for schools and to identify teacher and pupil requirements, we used Requirements Engineering (RE), which is an approach to investigate, define, document, and maintain the requirements for the best desired solution. RE is not principally about just documenting requirements; instead, it focuses on understanding a business problem and providing a solution for it [34], [35]. The RE discipline has expanded over the last decade, and the process includes not only traditional techniques, such as interviews, surveys, and workshops [36] or viewpoint-oriented RE [37]. It has also inspired several new methods and models, for instance, GBRAM (goal-based requirement analysis method) [38], i* [39], and KAOS (knowledge acquisition in automated specification) [40]. There are two different main views on RE: problem-oriented, and solution-oriented RE [41], [42]. "Problem-oriented RE focuses more on investigating and documenting a problem domain. The requirements engineer identifies the different factors (reasons) for the problem, the relations between these factors, why this is seen as a problem, and who experiences these problems". "Goal-Oriented RE (GORE) is a prevalent and widely used technique within problem-oriented RE. Goals are considered as high-level objectives of the system, business, or organization that identify the reasons for the development of a system and help to make decisions at different levels within an enterprise" [43]. VanLamsweerde [44] gives a general description of GORE; which is also used as part of the GBRAM and KAOS models. Solution-oriented RE, on the other hand, uses traditional techniques for software engineering, in other words, object-oriented analysis [45] and structured analysis [46]. The requirements specification for a solution represents the system from the software engineers' perspective [47] (e.g. system specification, system functions, quality attributes of these functions) and defines the alternatives for the best solution of the problem. Hence, the generic RE process consists of the following functions:

- Requirements Elicitation

- Requirements Analysis

- Requirements Specification

- Requirements Validation. 
Within the RE domain, research is done in almost every field of business (such as transport, education, health care, etc.), but to the best of our knowledge no work has been done within the development of requirements models for Open Data usage in schools. Enterprise Architecture (EA) on the other hand, is the complete, consistent, and coherent set of methods, rules, models, and tools that guide the design, migration, implementation, and governance of business processes, organizational structures, information systems, and the technical infrastructure of an organization according to a vision [48], [49]. EA is the practice of analyzing, designing, planning, and implementing enterprise analysis to execute business strategies successfully. We choose to combine RE with EA [50] as EA can have a significant impact on the requirements engineering process [51]. In this article, we derived requirements of school teachers and pupils within an EA frame and we proposed a combined Enterprise Architecture Requirements Engineering (EAORE) approach that allow us to identify requirements within different layers of an EA framework.

For the representation of EA issues, we used a selected set of elements of the EA representation language ArchiMate [52], [53] shown in Figure 2 and for modeling, we used the Archi modeling tool [54].

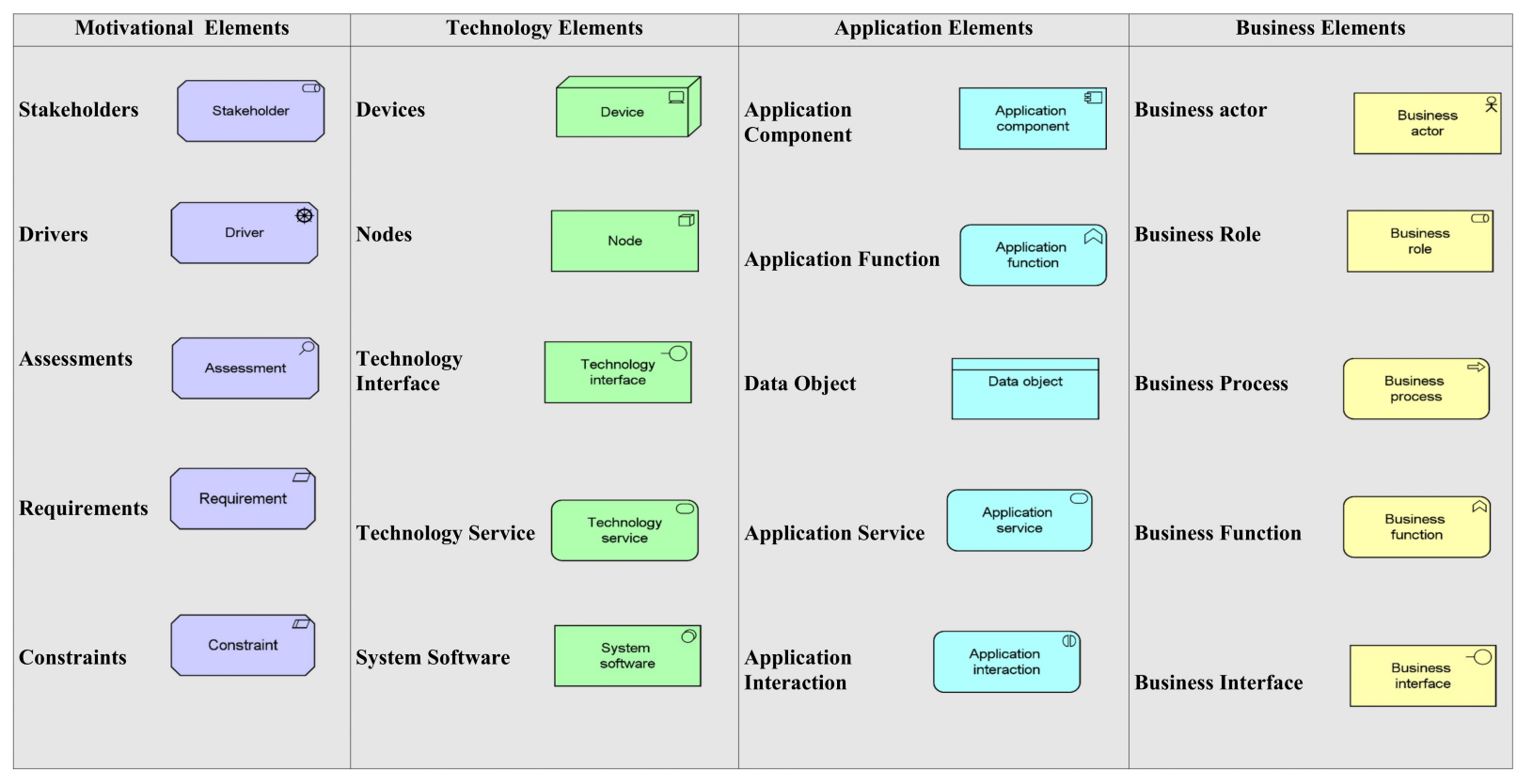

Figure 2. Selected set of elements from ArchiMate

In our study, to derive the enterprise architecture models, the requirements were identified through interviews with Danish public-school teachers, pilot tests, and observations with pupils, where the setup and participant details are given in [8] and [30]. Using EAORE, we explored and investigated the requirements of the Open Data interface for schools. To design the EA models in the EAORE approach, we used a four-layer enterprise architecture frame as shown in Figure 3. The models are discussed in the next section.

\section{Enterprise Architecture Models in RE for Open Data Usage in Schools}

Using EAORE, we developed a four-layer EA frame using the ArchiMate language, as shown in Figure 3. Our EA frame for Open Data usage in schools represents business, application, technology, and motivation layers. The sets of (related) EA element types serve as a frame of reference that guides the RE in each layer. We investigated requirements in each layer concerning different possible aspects shown in Figure 3. This layered view allows us to illustrate the motivation for the interface, potential concerns and assessments, technology requirements, and the usage of applications in 
business processes and the services they provide. In the remainder of this section, we will discuss the possible requirements, needs, and goals for each layer shown in Figure 3.

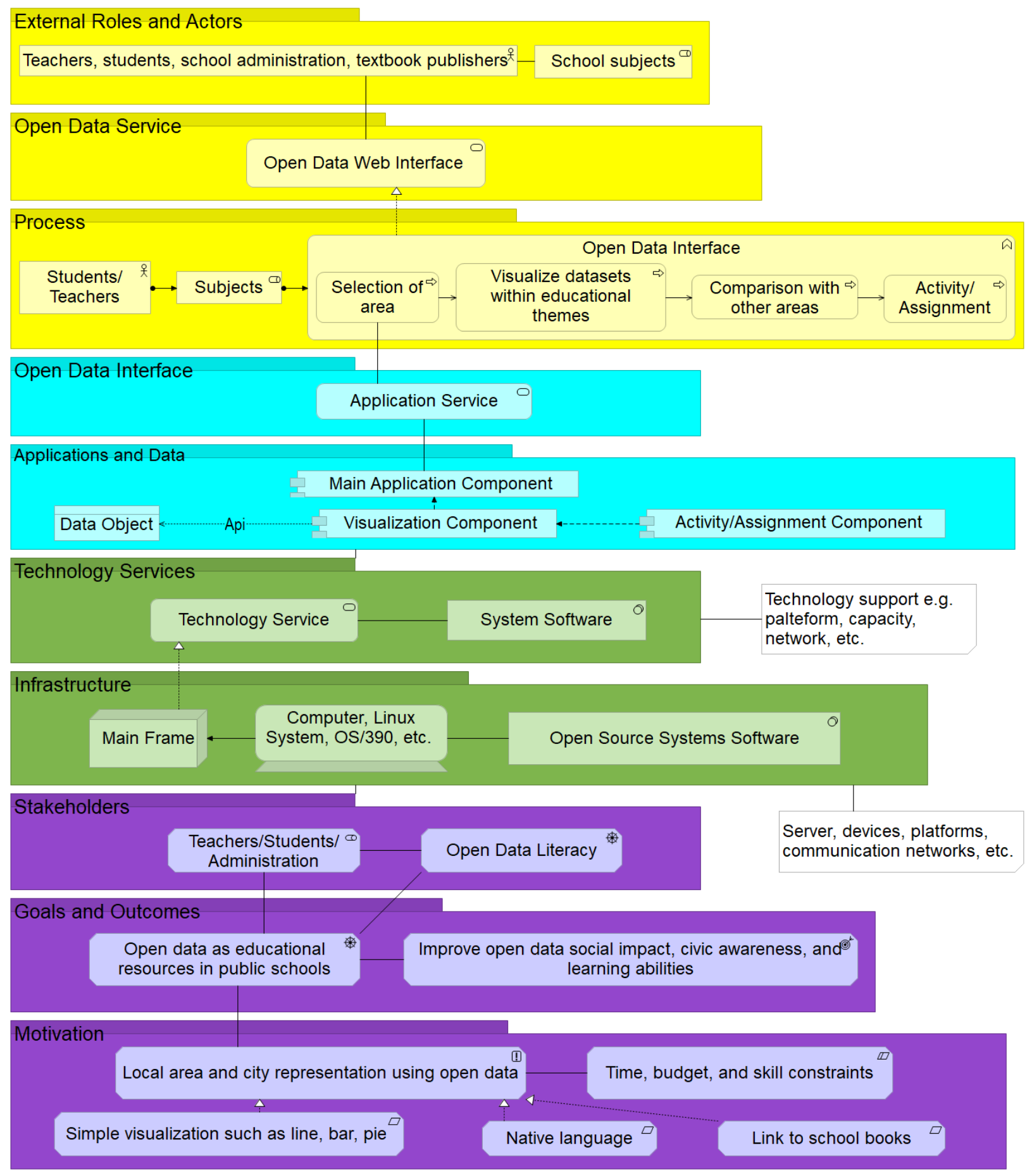

Figure 3. Layered view of EA for Open Data usage in schools

\subsection{Motivation Layer}

On the motivation layer, we have explored the stakeholders; their needs, concerns, and assessments; and how they interact with the system (Open Data interface). It also includes the motivational aspects (e.g. why teachers might use Open Data) and domain knowledge. The resulting models are shown in Figure 4 and Figure 5.

Figure 5 represents the RE issues for the needs and concerns shown in Figure 4. In our case, 


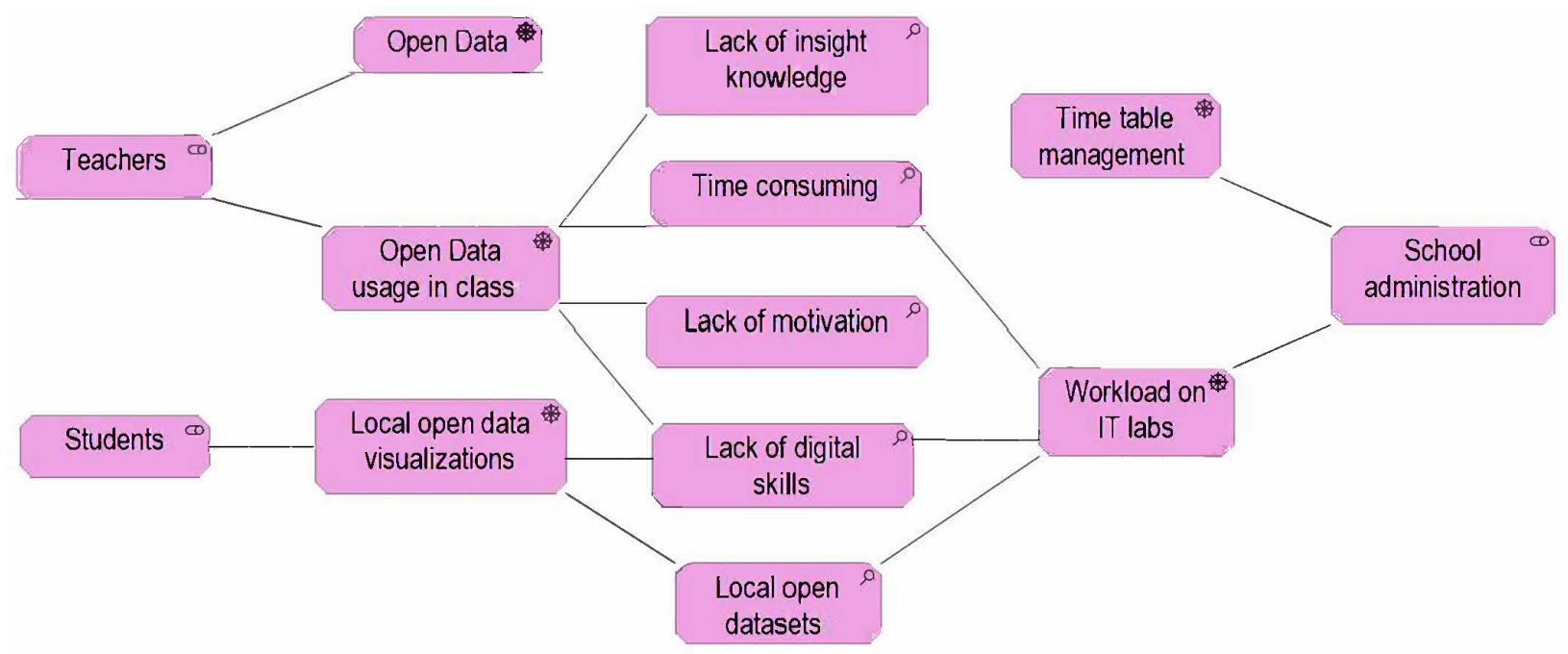

Figure 4. Stakeholder, concerns, and assessments

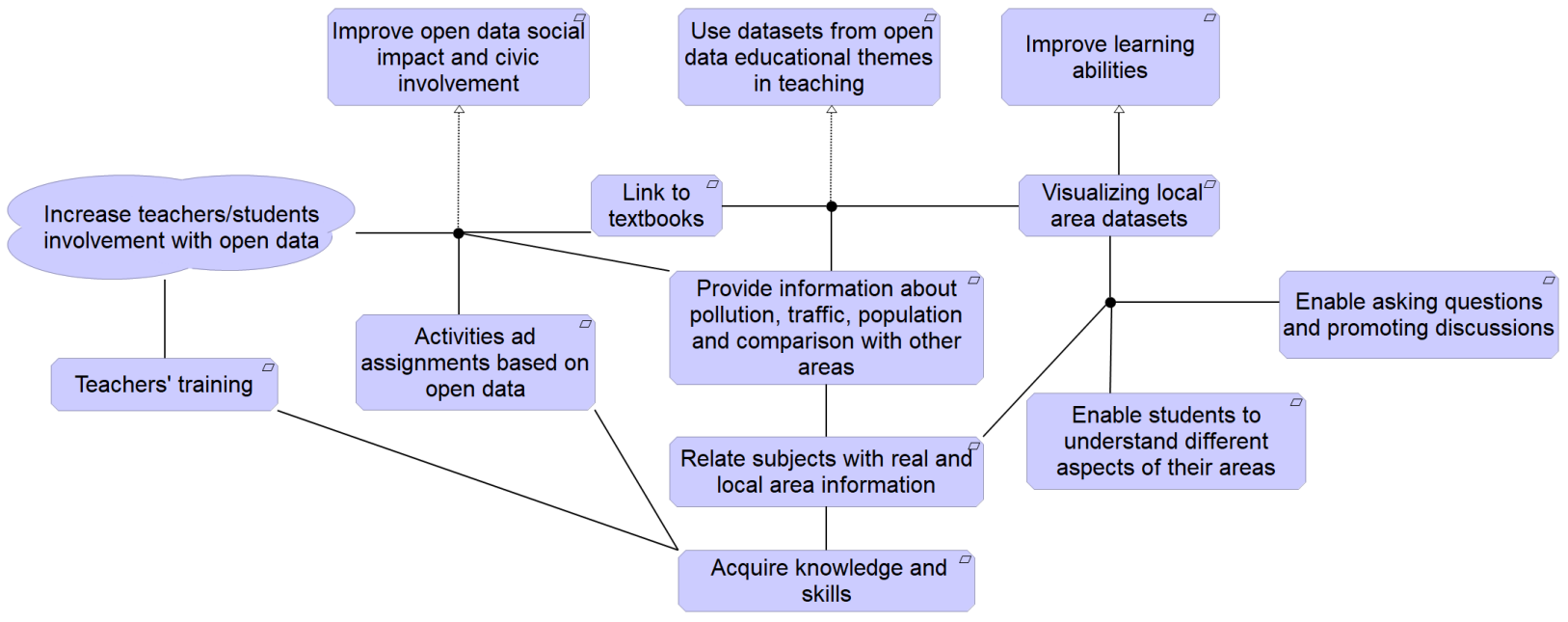

Figure 5. Motivational layer requirements model

we have identified three main internal stakeholders, namely, teachers, pupils, and the school administration, as well as textbook publishers as external stakeholders. Teachers are concerned with different data types, their graphs, the cleaning of datasets, and transformations of data into other formats. Pupils need simple interactive charts in their native language. Teachers are reluctant to spend a long time on searching datasets. These identified concerns from the pupils and teachers can provide with examples of important assessment criteria. For instance, there exist many open datasets with useful information that are not being exploited. These datasets can easily be used as free educational resources that can relate actual details to the study subjects to develop learning skills discussed in the previous sections. This would lead to the high-level goal to "increase Open Data social impact and youth engagement with Open Data." Teachers and pupils are not able to work directly with Open Data as they need simple presentations of open datasets in their native language. This can be a problem, as teachers are hesitant to spend a long time in identifying and visualizing the datasets, and the available open-source software for visualization is not available in their native language. Through goal refinement, we reached the goals that we want to introduce an Open Data interface that allows pupils and teachers to relate their subjects with actual information using Open Data as an educational resource and to improve civic awareness and youth engagement with Open Data. 


\subsection{Technology Layer}

On the technology layer, we explored what technology requirements are needed from the user and system perspectives. For instance, pupils and teachers must have easy access to computer labs, the internet, etc. Green elements in Figure 6 represent a technology layer model for Open Data usage in schools from the system perspective. For the Open Data web interface, open datasets within the educational domains are needed, such as datasets about pollution, geography, traffic and population. These datasets are available in different formats through the city's Open Data portal, such as CSV files, PDF files, or in other forms. The relevant Open Data within the educational themes can be accessed through Open Data portals and stored in cloud service. The open educational datasets are further transformed into local area datasets and stored in a database such as MongoDB, to visualize the local area information through the Open Data web interface. These open educational datasets are managed through a management interface. Open-source operating systems and visualization software are required to visualize the open datasets within the educational themes. Based on this technology layer model, prototypes for Open Data web interface will be developed and tested before the validation of the final interface in schools.

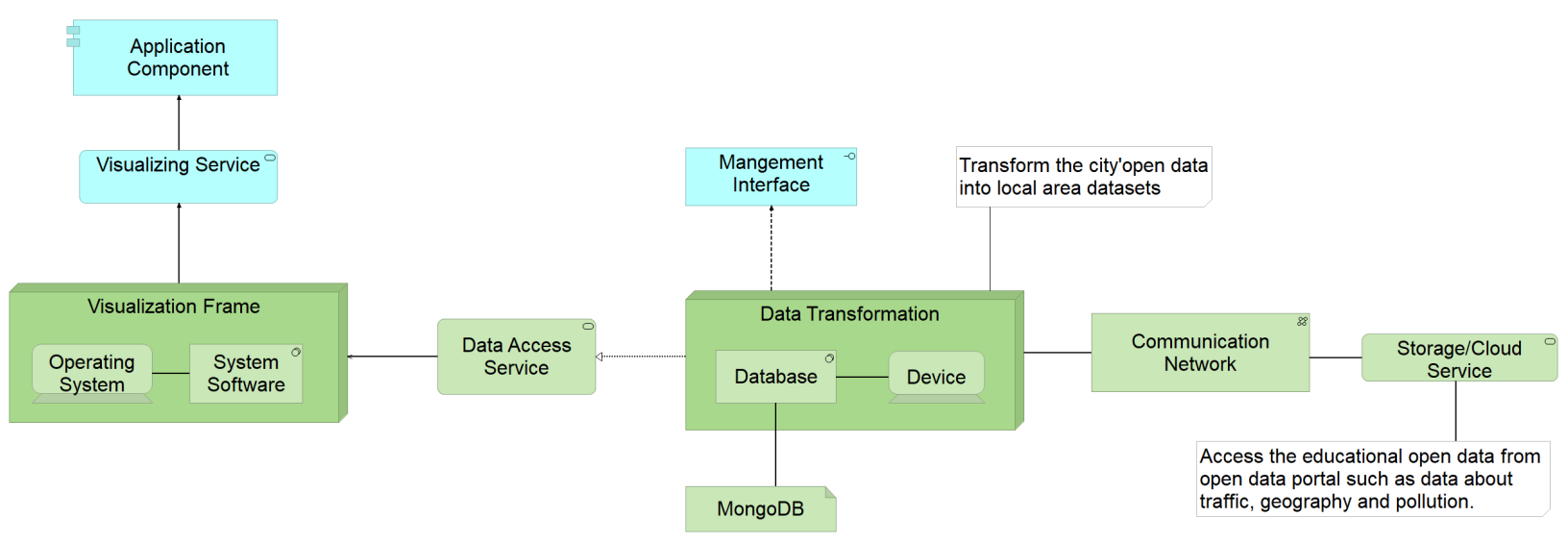

Figure 6. Technology layer requirements model

\subsection{Application Layer}

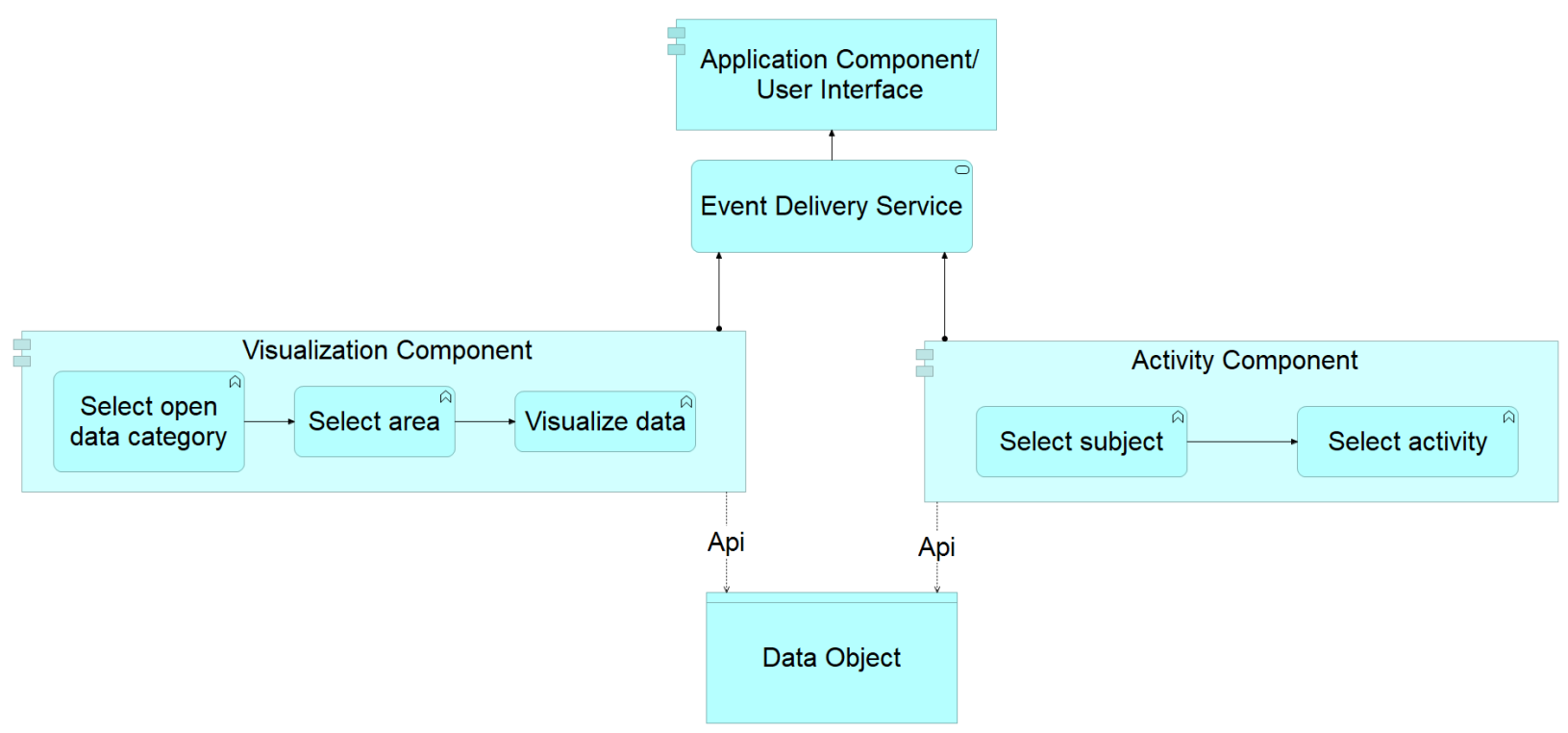

Figure 7. Application layer requirements model 
The application layer focuses on application components. It depends on requirements about language, appearance, and ease of use. The RE for this layer leads to the development of one main component and three sub-components, in other words, the data object, visualization component, and activity component. Teachers need local area open datasets in the form of simple visualizations (line, pie, bar) in their native language (Danish) to relate their subjects with actual information. The application should be easy to use without any programming expertise and with explained features.

\subsection{Business Layer}

The business layer leads towards the solution, in other words, an Open Data interface for the schools that enables teachers and pupils to benefit from the datasets. Figure 8 represents a usage view (model) for Open Data interface, and Figure 9 represents the business model for the Open Data interface. In the business layer, textbook publishers are identified as external actors. They will play

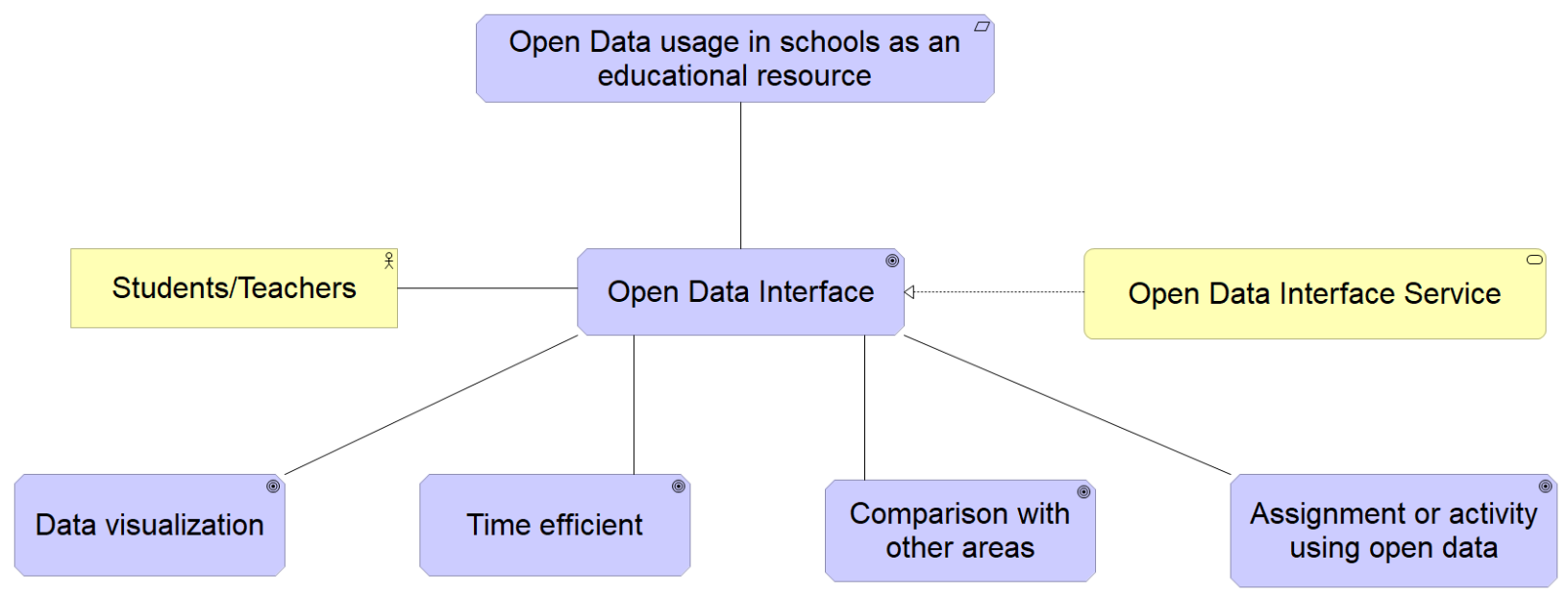

Figure 8. Open Data web interface usage view

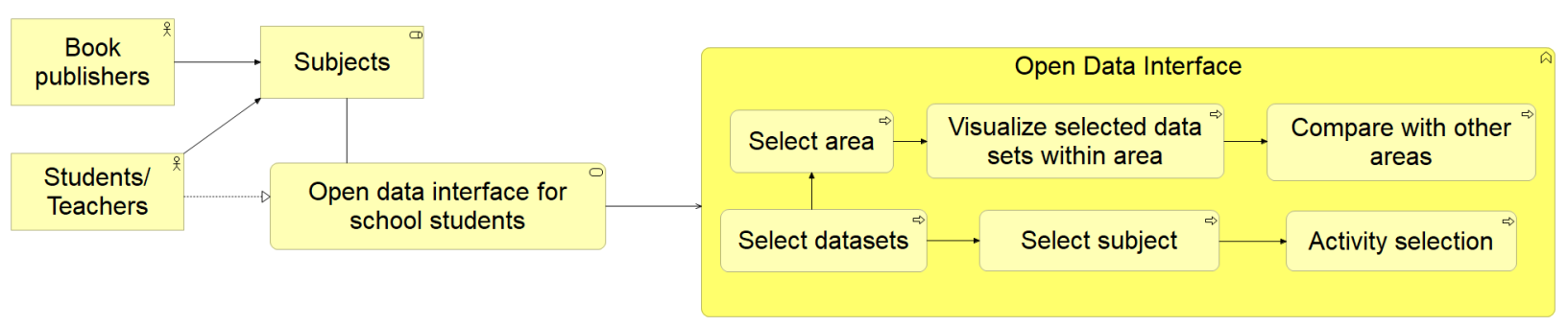

Figure 9. Open Data web interface for Open Data usage in schools (business layer view)

a central role for the active use of this interface. By linking different subject themes with the Open Data interface for activities and explanations, for instance, in geographic subjects, they can link the interface for the presentation of the respective local areas; or in science classes real, local examples could provide information about pollution, noise, or other environmental conditions. Such subjects as mathematics, science, geography, and social science act as business roles, as these subjects can use Open Data for visual presentation of local area aspects to facilitate educational activities at the school level.

\subsection{Evaluation of EAORE}

In the above sub-sections, we have presented models based on the EAORE approach for Open Data usage in schools. We have discussed the four layers that form the base for our frame and identified 
requirements in different aspects within these layers. The EAORE approach for Open Data usage in schools is flexible and could be used by other countries to extend the potentials of Open Data at the school level as an educational resource. By using EAORE, we covered motivational, application, technical, and business aspects that enabled us to make a transparent alignment among all these aspects. Using this approach, we derived precise requirements at different layers that are aligned with each other in the form of models. These models will help us to ensure that the need for Open Data usage will be met in an efficient, sustainable, and adaptable manner. Using the EAORE approach, we can easily trace and change requirements at different stages of development of the Open Data web interface. We can also save time, for instance, we can identify requirements at different layers and change or validate them easily at any layer using less time than needed to compare descriptions in text documents. The approach is easy to adopt, and in the future when we extend our research work (with more cases), we will also consider a requirements management system based on this approach. Currently, this article represents only a case-specific model; we will elaborate EA models and develop an analysis mechanism for more formal EA analysis in future work. It has to be noted that there are many relationships between elements of different layers of the frame. However, we showed only some of them to keep the discussion as simple as possible.

\section{Open Data Web Interface (Prototype) For Danish Public Schools}

In this section, we describe the design for the Open Data web interface (reflected by its first prototype) according to the identified requirements through our EAORE approach. The aim of developing the Open Data web interface is to link the Open Data educational themes with textbooks, as there exists no resource that provides real information of respective cities and municipalities to the young school pupils in the form of simple visuals and graphs. This interface will provide exciting information about cities as part of teaching subjects, for instance, information about the population as part of the geography subject. Figure 10 shows an overview of the interface (displayed in English for the purpose of this article). The main page has navigation to cities, activities and uploading blogs related to Open Data usage in schools. Different activities within the subject domains are designed to engage pupils actively and to provide hands-on experience. For instance, this could

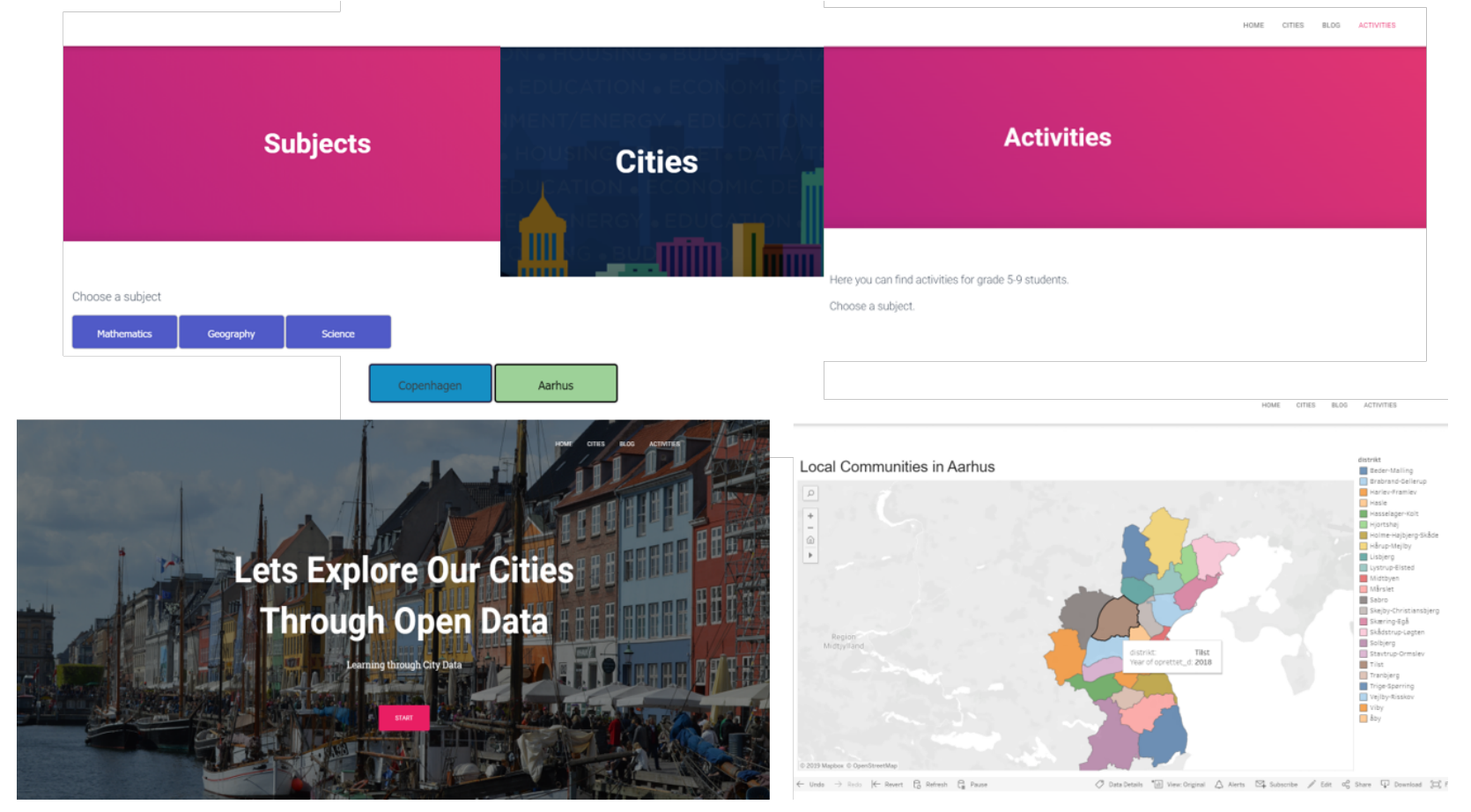

Figure 10. Open Data web interface 
include the collection of data using a notebook and comparing it with existing data through the web interface. Moreover, it also provides an opportunity for teachers to share their experiences with other teachers in the community in the form of blogs.

\subsection{Design Goals and the Prototype}

\subsubsection{Relationship between Open Data Visualizations and Subjects}

The main goal is to provide respective information of cities as part of teaching subjects. We have identified four educational Open Data themes corresponding to basic teaching subjects [30] in public schools: science, mathematics, social sciences, and geography. For instance, the web interface provides current information about pollution levels as part of the science subject.

\subsubsection{Access to Open Data of Different Cities}

The web interface also allows pupils and teachers to explore interesting information about other cities and municipalities. Currently, the interface provides access to two bigger cities of Denmark, Copenhagen and Aarhus, but can also be extended to other cities. Different views of the interface are shown in Figure 10.

\subsubsection{Simple and Interactive Visualizations}

The web interface provides complex and interesting information in the form of simple interactive graphs and visualizations. We used the Tableau software ${ }^{5}$ to visualize the data and integrate it with the web interface. This feature provides an opportunity for pupils and teachers to edit, share, download, and re-draw the graphs.

\subsubsection{Activities According to Grade Level}

In the activity component (see Figure 10), activities were designed for pupils according to their class level (e.g. from fifth to ninth grade). For instance, fifth grade pupils used the visualizations as a source of information, while pupils in the sixth grade not only interpreted the visualizations but could also answer some questions related to the visualizations.

\subsubsection{Native Language}

The interface uses the Danish language, so pupils and teachers in Danish public schools can easily interact and understand the provided information.

\subsubsection{Interface Architecture}

The Open Data web interface was developed with the idea of using open source tools and software that would allow school teachers and pupils to develop twenty-first-century learning skills. Tableau is used as a visualization tool as it provided free academic licenses for both pupils and teachers. Public schools can easily adapt it for data visualization purposes as an extra side tool. The architecture includes:

- Apache/2.4.41 (Win64)

- OpenSSL/1.1.1c

- PHP/7.3.9

- MySQL (database)

- Tableau (visualization software).

\footnotetext{
${ }^{5}$ https://www.tableau.com/
} 
The Tableau software is used to visualize the open datasets. The datasets are saved in a MySQL database after cleaning. Users can use different user-friendly features of Tableau to edit or modify the visuals and can also download the data.

In this section, we have presented the Open Data web interface that will allows teachers and pupils to interact actively and easily with real information on their own cities as part of teaching subjects. The intention is that teachers do not need any additional skills or time to work with Open Data as part of their teaching assignments. However, the prototype will be further tested in schools regarding these features.

\section{Conclusion}

As society becomes increasingly digitized, it becomes essential to equip our future generations with digital and data skills to confront future challenges. Open Data is a valuable resource with potential possibilities for both governments and the public. Thus these openly available datasets could be used as a raw material to develop twenty-first-century learning skills. The Open Data can be used as an educational resource to support teaching and learning activities as part of teaching subjects, for instance, mathematics, science, and geography. However, in general, teachers and educators are not well aware of these open datasets and associated opportunities as an educational resource. The designed Open Data web interface works as a bridge between the educational potential of Open Data and its use by the pupils as part of teaching subjects.

In this article, we have provided a systematic literature review on Open Data usage in the education domain and presented the design and a prototype for an Open Data web interface based on EAORE approach. We investigated the teacher and student needs and requirements to stimulate the use of Open Data as an educational resource in Danish public schools. We proposed and used the EAORE approach and framework for EA oriented RE for Open Data usage in Schools. The use of EA models helped to identify the requirements regarding different aspects such as motivation, technology, application, and solution aspects. Our EAORE approach has several potential advantages: time-saving, easiness of traceability, and flexibility of modeling, as discussed in Section 4. The Open Data web interface will allow both pupils and teachers to experiment with these datasets as part of their everyday learning and to take benefits from the potentials of Open Data as educational material.

Open Data has also another important aspect, i.e. economic benefits as discussed in [4]. With the use of Open Data at the school level, we could also have a positive influence on this aspect. Teachers will have easy access to relevant real information and pupils or students may make better decisions in solving their real-world problems. In the future, we are also interested in addressing some economic benefits deriving from Open Data usage in the schools. For instance, during the testing phase of the Open Data web interface, we will also analyze how students could identify local area problems and create proposals for solving those problems, such as how they could contribute to reducing the energy use in schools and thus reducing the climate impact. This can potentially affect civic awareness and have economic effects (by reducing energy expenditure).

In the future, we will elaborate on the approach discussed in this article after testing it with more cases and also will use it for designing a requirements management system. To further validate the Open Data web interface solution, we will test its different parts in schools. This phase will help us to explore and identify new problems based on the proposed solutions. Based on these new problems, revised prototypes will lead us towards the final development of the interface. The interface will not only provide the access to original and interesting information about cities and local municipalities but will also help to develop learning and digital skills and bring more awareness among the younger generation of school pupils about their communities and cities. 


\section{Acknowledgment}

The research work is supported by Community Drive Project, Aalborg University, Denmark. We thank all the participants contributing to this research work including the Danish public schools, teachers and pupils as well as the anonymous reviewers.

\section{References}

[1] M. Saddiqa, M. Kirikova, and J. M. Pedersen, "Enterprise architecture oriented requirements engineering for open data usage in schools," in International Conference on Business Informatics Research. Springer, 2019, pp. 135-147. [Online]. Available: https://doi.org/10.1007/ 978-3-030-31143-8_10

[2] R. Kitchin, The data revolution: Big data, open data, data infrastructures and their consequences. Sage, 2014. [Online]. Available: https://doi.org/10.4135/9781473909472

[3] M. Kassen, "A promising phenomenon of open data: A case study of the chicago open data project," Government Information Quarterly, vol. 30, no. 4, pp. 508-513, 2013. [Online]. Available: https://doi.org/10.1016/j.giq.2013.05.012

[4] M. Janssen, Y. Charalabidis, and A. Zuiderwijk, "Benefits, adoption barriers and myths of open data and open government," Information systems management, vol. 29, no. 4, pp. 258-268, 2012. [Online]. Available: https://doi.org/10.1080/10580530.2012.716740

[5] G. Cordasco, R. De Donato, D. Malandrino, G. Palmieri, A. Petta, D. Pirozzi, G. Santangelo, V. Scarano, L. Serra, C. Spagnuolo et al., "Engaging citizens with a social platform for open data," in Proceedings of the 18th Annual International Conference on Digital Government Research. ACM, 2017, pp. 242-249. [Online]. Available: https://doi.org/10.1145/3085228.3085302

[6] Y. Anokwa, C. Hartung, W. Brunette, G. Borriello, and A. Lerer, "Open source data collection in the developing world," Computer, vol. 42, no. 10, pp. 97-99, 2009. [Online]. Available: https://doi.org/10.1109/MC.2009.328

[7] J. Atenas and L. Havemann, Open data as open educational resources: case studies of emerging practice. Open Knowledge-Open Education Working Group, 2015. [Online]. Available: https://doi.org/10.5944/openpraxis.7.4.233

[8] M. Saddiqa, B. Larsen, R. Magnussen, L. L. Rasmussen, and J. M. Pedersen, "Open data visualization in danish schools: A case study," in Proceedings of 27th International Conference in Central Europe on Computer Graphics, Visualization and Computer Vision. Václav Skala-UNION Agency, 2019, pp. 17-26. [Online]. Available: https://doi.org/10.24132/CSRN.2019.2902.2.3

[9] UN. Education: Open data in schools. [Online]. Available: https://www.europeandataportal.eu/en/ highlights/open-data-schools

[10] AAU. Community drive. [Online]. Available: https://www.communitydrive.aau.dk/

[11] B. Alper, N. H. Riche, F. Chevalier, J. Boy, and M. Sezgin, "Visualization literacy at elementary school," in Proceedings of the 2017 CHI Conference on Human Factors in Computing Systems. ACM, 2017, pp. 5485-5497. [Online]. Available: https://doi.org/10.1145/3025453.3025877

[12] A. Vetrò, L. Canova, M. Torchiano, C. O. Minotas, R. Iemma, and F. Morando, "Open data quality measurement framework: Definition and application to open government data," Government Information Quarterly, vol. 33, no. 2, pp. 325-337, 2016. [Online]. Available: https://doi.org/10.1016/j.giq.2016.02.001

[13] H. Dong, G. Singh, A. Attri, and A. El Saddik, "Open data-set of seven canadian cities," IEEE Access, vol. 5, pp. 529-543, 2016. [Online]. Available: https://doi.org/10.1109/ACCESS.2016.2645658 
[14] I. Safarov, A. Meijer, and S. Grimmelikhuijsen, "Utilization of open government data: A systematic literature review of types, conditions, effects and users," Information Polity, vol. 22, no. 1, pp. 1-24, 2017. [Online]. Available: https://doi.org/10.3233/IP-160012

[15] B. Ubaldi, "Open government data," $O E C D$, no. 22, pp. 1-61, 2013. [Online]. Available: https://www.oecd-ilibrary.org/content/paper/5k46bj4f03s7-en

[16] M. A. Hossain, Y. K. Dwivedi, and N. P. Rana, "State-of-the-art in open data research: Insights from existing literature and a research agenda," Journal of organizational computing and electronic commerce, vol. 26, no. 1-2, pp. 14-40, 2016. [Online]. Available: https://doi.org/10.1080/10919392.2015.1124007

[17] Y. Charalabidis, C. Alexopoulos, and E. Loukis, "A taxonomy of open government data research areas and topics," Journal of Organizational Computing and Electronic Commerce, vol. 26, no. 1-2, pp. 41-63, 2016. [Online]. Available: https://doi.org/10.1080/10919392.2015.1124720

[18] M. J. Grant and A. Booth, "A typology of reviews: an analysis of 14 review types and associated methodologies," Health Information \& Libraries Journal, vol. 26, no. 2, pp. 91-108, 2009. [Online]. Available: https://doi.org/10.1111/j.1471-1842.2009.00848.x

[19] V. Braun and V. Clarke, "Using thematic analysis in psychology," Qualitative research in psychology, vol. 3, no. 2, pp. 77-101, 2006. [Online]. Available: https://doi.org/10.1191/1478088706qp063oa

[20] J. Atenas, L. Havemann, and E. Priego, "Open data as open educational resources: Towards transversal skills and global citizenship," Open praxis, vol. 7, no. 4, pp. 377-389, 2015.

[21] T. Coughlan, "The use of open data as a material for learning," Educational Technology Research and Development, pp. 1-29, 2019. [Online]. Available: https://doi.org/10.1007/s11423-019-09706-y

[22] A. Manca, J. Atenas, C. Ciociola, and F. Nascimbeni, "Critical pedagogy and open data as means for educating to social cohesion," Italian Journal of Educational Technology, pp. 111-115, 2017.

[23] T. Renuka, C. Chitra, T. Pranesha, M. Shivakumar et al., "Open data usage by undergraduate students," in Proceedings of 5th IEEE International Conference on MOOCs, Innovation and Technology in Education (MITE). IEEE, 2017, pp. 46-51. [Online]. Available: https://doi.org/10.1109/MITE.2017.00014

[24] K. Shamash, J. P. Alperin, and A. Bordini, "Teaching data analysis in the social sciences: A case study with article level metrics," in Open Data as Open Educational Resources: Case studies of emerging practice, 2015, ch. 3, pp. 49-55.

[25] M. Love, C. Boisvert, E. Uruchurtu, and I. Ibbotson, "Nifty with data: can a business intelligence analysis sourced from open data form a nifty assignment?" in Proceedings of the 2016 ACM Conference on Innovation and Technology in Computer Science Education. ACM, 2016, pp. 344-349. [Online]. Available: https://doi.org/10.1145/2899415.2899431

[26] T. Coughlan, "Using open data as a material for introductory programming assignments," in Open Data as Open Educational Resources: Case studies of emerging practice, 2015, ch. 2, pp. 38-48.

[27] R. Pérez-del Hoyo and M. Andújar-Montoya, "Towards innovative learning through the use of open data in engineering education," in INTED2017 Proceedings, ser. 11th International Technology, Education and Development Conference. IATED, 6-8 March 2017, pp. 6074-6081. [Online]. Available: http://dx.doi.org/10.21125/inted.2017.1420

[28] C. Anslow, J. Brosz, F. Maurer, and M. Boyes, "Datathons: an experience report of data hackathons for data science education," in Proceedings of the 47th ACM Technical Symposium on Computing Science Education. ACM, 2016, pp. 615-620. [Online]. Available: https://doi.org/10.1145/2839509.2844568 
[29] A. Wolff, J. J. C. Montaner, and G. Kortuem, "Urban data in the primary classroom: bringing data literacy to the uk curriculum," The Journal of Community Informatics, vol. 12, no. 3, pp. 1-10, 2016.

[30] M. Saddiqa, L. Rasmussen, R. Magnussen, B. Larsen, and J. M. Pedersen, "Bringing open data into danish schools and its potential impact on school pupils," in Proceedings of the 15th International Symposium on Open Collaboration, ser. OpenSym '19. ACM, 2019, pp. 9:1-9:10. [Online]. Available: http://doi.acm.org/10.1145/3306446.3340821

[31] I. Dunwell, R. Dixon, K. C. Bul, M. Hendrix, P. M. Kato, and A. Ascolese, "Translating open data to educational minigames," in Proceedings of 11th International Workshop on Semantic and Social Media Adaptation and Personalization (SMAP). IEEE, 2016, pp. 145-150. [Online]. Available: https://doi.org/10.1109/SMAP.2016.7753400

[32] M. G. Friberger and J. Togelius, "Generating game content from open data." in FDG, 2012, pp. 290-291. [Online]. Available: https://doi.org/10.1145/2282338.2282404

[33] J. D. Teresco, "Highway data and map visualizations for educational use," in Proceedings of the 43rd ACM technical symposium on Computer Science Education. ACM, 2012, pp. 553-558. [Online]. Available: https://doi.org/10.1145/2157136.2157295

[34] I. K. Bray, An introduction to requirements engineering. Pearson Education, 2002.

[35] M. Jackson, Software Requirements and Specifications: A lexicon of practice, principles and prejudices. Addison-Wesley, 1995.

[36] K. Pohl, Requirements Engineering: Fundamentals, Principles, and Techniques, 1st ed. Springer Publishing Company, Incorporated, 2010.

[37] G. Kotonya and I. Sommerville, "Requirements engineering with viewpoints," vol. 11, pp. 5-18, 1996. [Online]. Available: https://doi.org/10.1049/sej.1996.0002

[38] E. Kavakli, "Goal-oriented requirements engineering: A unifying framework," vol. 6, pp. 237-251, 2002. [Online]. Available: https://doi.org/10.1007/PL00010362

[39] S. Eric, P. Giorgini, N. Maiden, and J. Mylopoulos, Social modeling for requirements engineering. Mit Press, 2011.

[40] W. Heaven and A. Finkelstein, "Uml profile to support requirements engineering with kaos," vol. 151, pp. 10-27, 2004. [Online]. Available: https://doi.org/10.1049/ip-sen:20040297

[41] R. J. Wieringa, P. Fraternali, N. Koch, and M. Wirsing, "Requirements engineering: Problem analysis and solution specification (extended abstract)," vol. 3140, pp. 13-16, 2004. [Online]. Available: https://doi.org/10.1007/978-3-540-27834-4_3

[42] A. Aurum, R. Jeffery, C. Wohlin, and M. Handzic, Managing software engineering knowledge. Springer Science \& Business Media, 2013.

[43] A. Van Lamsweerde, "Goal-oriented requirements engineering: a guided tour," pp. 249-262, 2000. [Online]. Available: https://doi.org/10.1109/ISRE.2001.948567

[44] A. Van Lamsweerde, Requirements engineering: From system goals to UML models to software. Chichester, UK: John Wiley \& Sons, 2009, vol. 10.

[45] T. C. Lethbridge and R. Laganiere, Object-oriented software engineering. McGraw-Hill New York, 2005.

[46] J. Dick, E. Hull, and K. Jackson, Requirements engineering. Springer, 2017. [Online]. Available: https://doi.org/10.1007/978-3-319-61073-3

[47] B. Nuseibeh, "Weaving together requirements and architectures," vol. 34, pp. 115-119, 2001. 
[48] M. E. Iacob, L. O. Meertens, H. Jonkers, D. A. Quartel, L. J. Nieuwenhuis, and M. Van Sinderen, "From enterprise architecture to business models and back," Software \& Systems Modeling, vol. 13, no. 3, pp. 1059-1083, 2014.

[49] H. Jonkers, M. Lankhorst, R. Van Buuren, S. Hoppenbrouwers, M. Bonsangue, and L. Van Der Torre, "Concepts for modeling enterprise architectures," International Journal of Cooperative Information Systems, vol. 13, no. 03, pp. 257-287, 2004. [Online]. Available: https://doi.org/10.1142/S0218843004000985

[50] W. Engelsman, D. Quartel, H. Jonkers, and M. van Sinderen, "Extending enterprise architecture modelling with business goals and requirements," Enterprise Information Systems, vol. 5, no. 1, pp. 9-36, 2011. [Online]. Available: https://doi.org/10.1080/17517575.2010.491871

[51] D. Marosin, M. Van Zee, and S. Ghanavati, "Formalizing and modeling enterprise architecture (ea) principles with goal-oriented requirements language (grl)," in International Conference on Advanced Information Systems Engineering. Springer, 2016, pp. 205-220. [Online]. Available: https://doi.org/10.1007/978-3-319-39696-5_13

[52] T. O. Group. Archimateó 3.0.1 specification. [Online]. Available: https://pubs.opengroup.org/ architecture/archimate3-doc/

[53] M. M. Lankhorst, H. A. Proper, and H. Jonkers, "The anatomy of the archimate language," International Journal of Information System Modeling and Design (IJISMD), vol. 1, no. 1, pp. 1-32, 2010. [Online]. Available: https://doi.org/10.4018/jismd.2010092301

[54] Archi. Open source archimate modelling. [Online]. Available: https://www.archimatetool.com/ 